\title{
AS MÚLTIPLAS FACES DO LIVRO E DA CULTURA ESCRITA
}

\section{THE MULTIPLE FACES OF THE BOOK AND THE WRITTEN CULTURE}

\author{
Maria Celeste Mira (PUC-SP)* \\ Andréa Borges Leão (UFC)**
}

\section{O mercado editorial brasileiro na atualidade}

Um dos lamentos mais correntes e consensuais da geração de intelectuais que conheceu tardiamente o computador e a internet diz respeito ao fim das livrarias. Obviamente, as queixas se dirigem ao fechamento de várias livrarias físicas, nas quais se folheiam e adquirem livros e outros materiais impressos, CDs, DVDs (para mencionar apenas as mídias mais recentes); onde, vez por outra, encontra-se amigos e toma-se um café. Alguns costumam levar seu notebook ou tablet para trabalhar ou ler um pouco no local. A lástima é compreensível. Trata-se da suposta extinção de um dos principais elementos que compõe seu ecossistema.

No entanto o clamor dos frequentadores de livrarias não é mera fantasia. A partir de 2018, o mercado editorial do país evidencia mais uma de suas crises, especialmente em relação às livrarias. Neste ano, as redes Cultura e Saraiva, então responsáveis pela venda no varejo de $40 \%$ dos livros, segundo a imprensa, "entraram em processo de recuperação judicial, fechando lojas em dezenas de cidades, demitindo em massa e dando um calote de mais de R\$ 300 milhões nas editoras" (TRIGO, 2018). O ano de 2018 também assistiu à falência da Laselva e da Bookpartners, uma das mais relevantes distribuidoras do país (PUBLISHNEWS, 2018). Em consequência, editoras importantes do mercado nacional foram profundamente impactadas.

Com a crise da Saraiva e da Cultura, as editoras enxugaram os lançamentos de 2018 e 2019, diminuíram as tiragens, demitiram. Por causa da recuperação judicial das duas, a Companhia das Letras começa o ano com menos R\$ 26 milhões na conta. A Record, com menos R\$ 22 milhões e a Sextante, com menos R\$ 18 milhões (RODRIGUES, 2018).

\footnotetext{
* É livre-docente em Antropologia e Sociologia da Cultura pela Pontifícia Universidade Católica de São Paulo. Possui doutorado em Ciências Sociais pela Universidade Estadual de Campinas e mestrado e bacharelado em Ciências Sociais pela PUC-SP. É professora do Departamento de Antropologia e do Programa de Estudos Pós-Graduados em Ciências Sociais da PUC/SP. E-mail: celestemira@gmail.com.

** Doutora em Sociologia pela Universidade de São Paulo; mestre e bacharel em Sociologia pela Universidade Federal do Ceará. Realizou estágio pós-doutoral em História Cultural no CRBC, da École des Hautes Études en Sciences Sociales, Paris. É professora do Departamento de Ciências Sociais e do PPGS da Universidade Federal do Ceará. E-mail: aborgesleao@gmail.com
} 
Algumas livrarias, porém, demonstraram bons resultados mesmo em meio à crise do mercado. Por exemplo, a Martins Fontes Paulista registrou, até a véspera do Natal de 2018, “crescimento de 56\% no faturamento em relação ao mesmo período de 2017" (RODRIGUES, 2018). Vale ressaltar que os negócios da Martins Fontes são focados especificamente em livros, diferentemente da Livraria Cultura ou da Saraiva.

Seguindo a tendência mundial de concentração e internacionalização e, sobretudo, como tentativa de fortalecimento do mercado editorial brasileiro, as aquisições e fusões se destacaram:

A Kroton, gigante do segmento de educação superior, comprou a Somos, igualmente gigante na educação básica, o que elevou a Kroton a maior grupo de educação privada do país. O outro momento importante (...) foi quando a Penguin Random House assumiu o controle da Companhia das Letras (PUBLISHNEWS, 2018).

Outro fator importante para a explicação deste quadro é a paulatina mudança nas formas de aquisição dos livros. As vendas de livros pela internet (e-commerce) e a consolidação da Amazon no país certamente geraram mudanças importantes no mercado editorial brasileiro. Em relação ao e-commerce, como mostrou a pesquisa Retratos da Leitura no Brasil 4, (FAILLA, 2016), dentre aqueles que já haviam comprado livros em 2015, 44\% afirmaram tê-los adquirido em livrarias físicas e $15 \%$ online.

A compra de livros pela rede mundial até 2016 se mostrava expressiva. Embora representasse apenas $4 \%$ do faturamento das empresas de e-commerce, a categoria "livros, assinaturas e apostilas" ocupou a primeira posição em relação ao volume de pedidos realizados na Internet no $1^{\circ}$ semestre de 2016, de acordo com a $34^{\text {a }}$ edição do relatório WebShoppers ${ }^{1}$ (EBIT, 2016, p. 21; RIELO, 2017).

Além do crescimento do e-commerce e do advento do e-book, a queda no faturamento do mercado editorial, a dependência das editoras das vendas para o governo e a crise econômica que vive o país foram fatores que contribuíram para criar o atual cenário tão desfavorável às livrarias físicas, mesmo as chamadas megastores, como a Saraiva e a Cultura que, além de livros, oferecem também CDs, DVDs, eletrônicos e até material de papelaria. Pela variedade de produtos que oferecem, elas podem também ter sido afetadas pelas novas tecnologias de streaming de música e vídeo, como o Spotify e o Netflix, de maneira que a compra de CDs e DVDs tenha sido substituída por esse tipo de assinatura. Outras tecnologias começaram igualmente a ganhar algum destaque no mercado editorial, como os audiolivros. Em 2018, a Feira do Livro de Frankfurt criou uma programação especial para eles. No mesmo ano, "duas plataformas internacionais anunciaram o seu desembarque no Brasil (...) Google com serviço a la carte e em parceria com Ubook e Tocalivros e, mais recentemente, a sueca Storytel" (PUBLISHNEWS, 2018).

1 "Realizado pela Ebit desde 2001, o Webshoppers é o relatório de maior credibilidade sobre o comércio eletrônico brasileiro e considerado a principal referência para os profissionais do segmento" (EBIT, 2016). 
Não obstante as pequenas livrarias também sofrem com o atual estado do mercado editorial. Bernardo Gurbanov, presidente da Associação Nacional de Livrarias, afirmou:

"A atual crise não é só das grandes. Trata-se de um processo iniciado nos anos 1980 que conjuga a tendência econômica à hiperconcentração com o advento das novas tecnologias e as modalidades de consumo delas decorrentes" (RODRIGUES, 2018).

Afetando sobretudo a cultura dos intelectuais acadêmicos, ou seja, a cultura letrada, que atinge seu auge no século XIX europeu, o livro impresso e as formas de leitura estão passando por mais um momento de transformação histórica, no qual se mesclam rupturas e permanências. O objetivo deste artigo/apresentação, e dos demais textos publicados neste dossiê, é lançar luz sobre o cenário contemporâneo a partir de diferentes espaços, temporalidades, objetos e pontos de vista.

\section{A cultura impressa, a educação, os meios eletrônicos e o Estado-Nação}

O atual estado do mercado editorial brasileiro é resultado de processo de mais longo prazo. Antes da atual crise, ele havia crescido. De acordo com pesquisa da Câmara Brasileira do Livro (2017a), entre 2006 e 2013, o setor livreiro cresceu 50,66\% no país, saltando de 318,56 milhões para 479,95 milhões de exemplares, somadas as aquisições do governo e do mercado. Após esse período, que corresponde, aproximadamente, ao segundo governo do presidente Luís Inácio Lula da Silva e ao primeiro mandato de Dilma Rousseff, as vendas começaram a cair, chegando a 385,09 milhões de exemplares em 2016, o que representava, então, uma redução de 19,77\% em apenas três anos. As vendas diretamente ao mercado, o que inclui as livrarias, já haviam entrado em queda dois anos antes, desde 2011, sofrendo a redução de 283,98 milhões para 226,92 milhões de exemplares vendidos em 2016. O número de vendas para o governo apresentou a mesma tendência: aumentou significativamente entre 2006 e 2013, ano em que atinge o seu ápice, com 200,31 milhões de exemplares.

Após este período que, não por acaso, corresponde exatamente à gestão de Fernando Haddad no Ministério da Educação, ou seja, de 2005 a 2012, as aquisições de livros por parte do governo declinam até atingirem, em 2016, o número de 158,47 milhões de exemplares. Embora não afete diretamente as livrarias, a retração dos investimentos governamentais influencia toda a cadeia produtiva do livro, contribuindo para o seu encolhimento. Ao final das contas, a queda do número de exemplares vendidos somada à diminuição de $34 \%$ no preço médio dos livros (2006-2018) fizeram com que o faturamento do setor editorial diminuísse $25 \%$ entre 2006 e 2018 (CÂMARA BRASILEIRA DO LIVRO et al., 2018) ${ }^{2}$.

De fato, a ampliação do mercado editorial brasileiro entre 2006 e 2013 foi conjuntural, resultando, em grande parte, de um conjunto de políticas públicas do governo federal. Deve-se levar em conta que o país vivia um ciclo de crescimento econômico, de políticas de inclusão

2 Foram consideradas as vendas das editoras tanto para o mercado como para o governo. 
social e educacional, responsáveis pela mobilidade social das classes de mais baixa renda e pela ampliação do acesso ao ensino superior. Embora sem dados precisos, a então presidenta da Câmara Brasileira do Livro, Karine Pansa, apontava como prováveis explicações para o crescimento das vendas de livros a diminuição do seu preço aliada ao aumento do poder aquisitivo da classe $\mathrm{C}$, na qual se situava $50 \%$ do público leitor brasileiro. Isto porque, os dados de pesquisa mostravam que as condições favoráveis não haviam ampliado o público leitor, mas levado apenas ao incremento da leitura por parte dos brasileiros que já tinham o hábito de ler livros impressos. A pesquisa do Instituto Pró-Livro, Retratos da Leitura no Brasil de 2012, revelava que, mesmo em números absolutos, o público leitor diminuíra de 95,6 milhões em 2007 para 88,5 milhões em 2011 (CHARÃO; COSTA, 2013). Prova disto é que o subsetor de obras gerais, onde se situa o leitor de livros impressos "por excelência", mesmo no momento de crescimento, entre 2006 e 2014, considerando-se as vendas diretas ao mercado, acumulou queda de 25\%. (CÂMARA BRASILEIRA DO LIVRO et al., 2018).

Como se sabe, do ponto de vista da "cultura letrada", à qual o livro, mais do que outros impressos de linguagem também imagética, está estreitamente vinculado, não se formam leitores em pouco tempo. Por mais que métodos inovadores possam abreviar o caminho ao conhecimento ilustrado, ele demanda tempo. Esse tempo, na modernidade clássica, tal como ocorreu na Europa, durou todo o século XIX, ao longo do qual se processa uma verdadeira revolução nas práticas de leitura provocada pelo boom dos meios impressos. Esse momento, que pode ser entendido como o berço da cultura popular de massa, é fruto da convergência de uma série de fatores de ordem técnica, como a introdução da prensa rotativa na produção dos periódicos (ORTIZ, 1991), de novas formas de financiamento (a publicidade); de distribuição (o trem que trouxe os quiosques de livros nas estações) para chegar até o leitor. E esse leitor está presente em número cada vez em maior e em lugares mais distantes à medida que a implantação do sistema de ensino público universal e gratuito avança por cada país, implantando uma única língua e uma única cultura nacional. Os casos mais exemplares são os da Inglaterra, sobre o qual Raymond Williams escreveu o livro The long revolution (1984), referindo-se à difusão e popularização da imprensa britânica; e o da França, onde jornais, revistas e livros conheceram a glória. Basta mencionar o título escolhido por dois autores importantes para definir o século XIX na França a respeito do livro, o meio de mais difícil difusão e popularização: A revolução do livro (ESCARPIT, 1976) e O triunfo do livro (LYONS, 1987).

Nesta dinâmica - central na constituição da modernidade capitalista - o ponto-chave é a educação, na expressão de Gellner (1993) o maior patrimônio que o homem moderno pode ter. A educação, na Europa Ocidental, frente às necessidades da Revolução Industrial e da Revolução Francesa, deixa de ser função da família e da comunidade no mundo tradicional, tornando-se encargo do sistema escolar. O Estado-Nação assume a educação universal como parte de seu próprio projeto. Além de produzir as novas classes sociais, era preciso, como já observaram vários historiadores, constituir, no espírito de cada habitante do território abrangido politicamente pelo 
Estado, o sentimento de nacionalidade. A ideia é sintetizada perfeitamente por Eugène Weber (apud LYONS,1987, p. 26): para produzir a integração nacional, a escola deveria "transformar os camponeses em franceses". O sistema educacional, portanto, surge como algo indissociável do Estado-Nação e do pacto da cidadania. Em contrapartida, o Estado-Nação oferece ao cidadão uma série de direitos e garantias quanto à sua liberdade, segurança, dignidade etc.

Não há dúvida de que todos os países do mundo são modernos. Se concordarmos com a ideia defendida por Renato Ortiz (1994) de que "mundialização da cultura" é expressão equivalente à "modernidade-mundo", é forçoso concluir que todas as formas de vida social foram integradas, de forma diversa e desigual, à modernidade ocidental, ou seja, ao capitalismo global. Porém os modos como se constituiu o modo de vida moderno em continentes e países, regiões e locais, em tempos e configurações históricas diferentes das do século XIX europeu é o que faz toda a diferença. Embora a dicotomia entre o "tradicional" e o "moderno" seja teoricamente superada, a comparação entre a "modernidade clássica" da Europa do século XIX e a "modernidade tardia", na falta de termo melhor, da América Latina, nos ajuda a entender certas questões insistentemente debatidas a respeito da cultura escrita ou do fato de o Brasil ser ou não um país de leitores - referindo-nos aqui à leitura de livros impressos.

Deste ponto de vista, é esclarecedor percebermos como se deu o projeto de construção do Estado-Nação no Brasil, em específico, em relação à internalização do sentimento de brasilidade, no qual, obviamente, os aspectos políticos e econômicos estão sempre envolvidos. Como se sabe, a construção da ideia de Brasil tem dois momentos fortes: a Era Vargas e o período da Ditadura Civil-Militar. Embora a "modernidade clássica" europeia tenha aparência democrática, sua "violência simbólica" (BOURDIEU, 2003) não foi menor que a exercida nesses dois períodos históricos autoritários no Brasil. De acordo com Anderson (1989), no processo de formação dos Estados-Nação na Europa, o número de línguas faladas caiu aproximadamente de 800 para 80 , o que levou ao extermínio de culturas ou modos de vida inteiros. No Brasil, Getúlio Vargas também proibiu outras línguas que não o português, em particular, o alemão, falado nas colônias de imigrantes do sul do país. Na Era Vargas, teve início o primeiro grande esforço de difusão do ensino fundamental no Brasil, com a criação do Ministério da Educação e Saúde e a Reforma Campos. O ensino fundamental, como analisou Antonio Candido (1984), chegou, quando muito, aos estratos médios da população, o que, para o índice de analfabetismo da época pode ser considerado um progresso. O mercado editorial, por sua vez, adquire bases mais sólidas, com a criação do INL, Instituto Nacional do Livro; com o estabelecimento do editor José Olympio no Rio de Janeiro; a inauguração da Biblioteca Mário de Andrade em São Paulo; com a publicação dos grandes romances e ensaios que se tornaram clássicos para os leitores brasileiros (PAIXÃO, 1995).

A partir da Ditadura Civil-Militar de 1964, apesar de programas paliativos como o Mobral, que logrou melhorar os índices de analfabetismo, a educação pública foi cada vez menos considerada no orçamento do Estado em todos os níveis, de modo que o Brasil manteve, 
ao longo do século XX, altos índices de analfabetismo. Mesmo assim, o momento foi muito favorável ao crescimento do mercado editorial. No período militar, não apenas os meios de comunicação, mas todos os setores da produção cultural cresceram de modo extraordinário. De acordo com Hallewell (1985), devido ao crescimento do ensino superior no país, o número de livros publicados no Brasil saltou de 43,6 milhões em 1966 para 245,4 milhões de exemplares em 1982. Como demonstrou Renato Ortiz (1988), todo o mercado editorial brasileiro se expandiu, tendo como melhor exemplo a Editora Abril. Apoiada no mercado de revistas e histórias em quadrinhos, que quintuplicou entre 1960 e 1985, passando de 104 para 500 milhões de exemplares em circulação (ORTIZ, 1988), a Abril foi também um grande caso de difusão do livro no período pós-64. A empresa criou um novo braço editorial para explorar a venda em bancas de fascículos e coleções que cobriram as áreas de literatura, teatro, filosofia, artes plásticas, música e outros clássicos. Muito dessa literatura se dirigia a uma classe média em ascensão que via no livro um símbolo de status e, por meio dele, poderia formar uma bela coleção encadernada para ornamentar a sala de visitas (HALLEWELL, 1985).

Por outro lado, a maioria dos brasileiros adquiria grande familiaridade com os meios eletrônicos, uma vez que a construção da nacionalidade de boa parte dos Estados latinoamericanos se dava através dos meios de comunicação. Martín-Barbero (1987) mostrou que estes foram os casos da Argentina, do Brasil, da Colômbia, do México, entre outros, países nos quais os indivíduos passaram a reconhecer sua nacionalidade nos filmes cinematográficos, nas novelas do rádio ou da televisão, nas músicas gravadas e tocadas nos meios eletrônicos, nas ruas, nos parques ou outros espaços de entretenimento. Se observarmos o caso brasileiro, veremos que, nos dois momentos em que o sentimento de nacionalidade foi exaltado e incentivado pelo Estado, os meios de comunicação ocuparam lugar central: o rádio, nos anos 1930/40, e a televisão, no pós-64. Com ou sem investimento na educação escolar, a constituição da brasilidade, nos dois momentos, não teria ocorrido sem os meios eletrônicos. Basta lembrar da encampação da Rádio Nacional pelo Estado Novo e a importância que teve a difusão de sua programação, devidamente censurada pelo DIP (Departamento de Imprensa e Propaganda), em quase todo o enorme território do país. Basta, para completar, recordar o papel desempenhado pela implantação do sistema nacional de televisão em todo o país, o qual, graças aos investimentos do governo federal, operava via satélite desde 1969, atingindo, no final dos anos 1970, cerca de 2/3 dos domicílios brasileiros. "Eu vi um Brasil na tevê" dizia um verso da música de Chico Buarque, "Bye, bye, Brasil", dando adeus a um país que se modernizava rapidamente, passando, em grande parte, direto da cultura oral para a cultura audiovisual.

\section{Livros e práticas de leitura na era das tecnologias digitais: uma nova mutação?}

Robert Escarpit (1976) sugere que o livro tenha passado por quatro mutações até o século XIX, advindas, cada uma delas, de uma inovação técnica aliada a um contexto histórico 
propício. Estas quatro fases teriam sido: a do volumem, a do códex, a do livro impresso e a da impressão mecânica. Embora cada uma dessas formas tenha uma longa história, pode-se dizer, de modo sintético, que o volumem era formado por um rolo de folhas de papiro, tendo sido utilizado em Atenas e depois em Roma até o século IV; então, um pergaminho cortado em folhas e costurado como um caderno dá origem ao códex, cuja circulação dura aproximadamente mil anos; na segunda metade do século XV, a técnica de impressão, que entrou para a história ligada ao nome de Gutenberg, marca, para vários autores, dentre os quais Lucien Febvre (1958), “o aparecimento do livro", ou seja, o surgimento do livro impresso a partir de caracteres móveis; para outros estudiosos de sua história, dentre os quais, como vimos, o próprio Escarpit, a quarta mutação viria com a impressão mecânica, ocasionando a "revolução do livro". Embora o códex tivesse um formato mais prático do que o volumem, ambos são livros manuscritos; a tipografia se impõe à caligrafia, possibilitando tiragens próximas de mil exemplares no século XVI e de dois a três mil no século XVIII. No entanto a imprensa de Gutemberg evoluiu lentamente durante os três séculos seguintes. Embora, por meio dela, o livro não fosse mais manuscrito, sua produção ainda envolvia muito trabalho manual. Esta situação muda radicalmente com a introdução da prensa rotativa. Enquanto a prensa manual alcançou a capacidade máxima de três mil folhas por dia, a prensa rotativa eleva esse número para dez mil por hora, em 1850 (ORTIZ, 1991).

A cada uma dessas mutações, correspondem novos leitores e novas práticas de leitura. $\mathrm{Na}$ Grécia e na Roma antiga, o volumem transmitia os conhecimentos da época ao círculo reduzido de letrados. Na Alta Idade Média, o códex, contendo os textos sagrados, os códigos jurídicos e a cultura erudita, era cuidadosamente preservado pelos clérigos, nos mosteiros e abadias, à distância do povo e da própria nobreza, revestindo-se de uma aura sagrada e profunda respeitabilidade. A partir do século XIII, de acordo com Jacques Le Goff (1984, p. 90), o surgimento do ofício de intelectual em torno das universidades faz com que o livro adquira uma nova dimensão: "deixa de ser objeto de luxo para passar a ser um instrumento". Os estudantes universitários têm necessidade de transportar e manusear os textos eruditos, utilizando, para tanto, a peça (pecia), um caderno de quatro folhas em pele de carneiro, cujo conjunto forma o exemplar. Contendo o texto oficial, o exemplar passa para a oficina dos copistas que reproduzem cada peça separadamente, acelerando o ritmo de trabalho. Escrito com pena de ave, em letra cursiva e num pergaminho mais branco e menos espesso, o livro diminui de tamanho, decrescendo também a importância das ilustrações, cujo espaço, muitas vezes, é deixado em branco para posterior preenchimento, se o leitor assim o desejar ${ }^{3}$.

O livro impresso, por sua vez, foi contemporâneo do Renascimento e da Reforma, representando para esses movimentos, nas palavras de Lucien Febvre (1958), o papel de "fermento na massa". Contribuindo para fixar as línguas e desenvolver as literaturas nacionais, o livro tem seu formato reduzido mais uma vez, tornando-se mais portátil. Como assinala Febvre

3 As ilustrações e iluminuras que adornavam os livros manuscritos são uma história à parte. Trata-se de uma verdadeira arte da Idade Média já estudada por diversos autores. 
(1958, p. 126-7), "deixa de aparecer como um objeto precioso que se consulta numa biblioteca: deseja-se cada vez mais trazê-lo consigo e transportá-lo facilmente a fim de consultá-lo e lê-lo em todo lugar e à toda hora”. Aos clérigos e intelectuais vêm se juntar os nobres e burgueses enriquecidos. O livro impresso se propaga também através da leitura em voz alta para os que não sabem ler, com as inúmeras edições da Bíblia e outros livros religiosos, dos almanaques e dos próprios clássicos antigos e medievais.

Já a introdução da impressão mecânica é considerada revolucionária por ter propiciado a popularização dos meios impressos. A partir do século XIX, a vendagem de jornais aumenta de forma explosiva, desta vez, por meio de formatos e gêneros populares, cujos exemplos mais notáveis são o folhetim e os faits divers. O livro encontra mais dificuldade na sua difusão devido ao preço mais elevado e às disputas entre autores e editores. Porém, na segunda metade do século, descobre vários caminhos, chegando aos leitores em fascículos e outros formatos menos dispendiosos; por meio de entregas domiciliares, de vendas em quiosques, nas ruas ou nas estações de trem, entre outros. Tanto os jornais quanto os livros se expandem apoiados numa miscelânea típica da literatura popular, ou seja, contos, baladas, almanaques, aventuras para jovens, histórias de assassinatos, dramas e execuções, sendo que a lista está longe de ser exaustiva.

Em uma perspectiva de longa duração, como a descrita acima, não se pode perder de vista que as mudanças técnicas na produção do livro não implicam o desaparecimento de práticas de leitura anteriores. Modos de apropriação passados e contemporâneos podem coexistir reciprocamente. Hoje, a leitura na tela do computador convive com a leitura do impresso, assim como a leitura silenciosa não se impôs totalmente a ponto de suprimir a leitura oral. O importante é que quando as técnicas mudam, lembra Roger Chartier (2001), mudam as atribuições, competências e relações entre os protagonistas do livro - o escritor, editor, livreiro, programador visual, o leitor, entre outros mediadores. Suas funções são deslocadas e substituídas na medida em que transformam as condições de produção e comércio. O livro é objeto material que enseja representações e dá lugar a práticas. Por isso, os atores que dão vida aos processos de sua publicação são responsáveis diretos pela construção dos sentidos dos textos que portam. Donald F. McKenzie (1991) chama a atenção para a importância das diferenças materiais entre textos e livros. Para o bibliógrafo inglês, os livros são um entre outros meios nos quais se inscrevem os textos manuscritos ou digitalizados, de modo que escritores não escrevem livros e, muito menos, são os únicos responsáveis pela construção da significação das obras. $\mathrm{O}$ leitor, com sua liberdade sempre controlada pelas convenções sócio-históricas (CHARTIER, 2002), tem aí um papel decisivo, ressignificando conteúdos ou imprimindo novos.

O mundo do livro diz muito sobre os níveis de escolarização, o acesso à cultura, ao conhecimento e à diversão. As possibilidades abertas pelas novas tecnologias da informação ampliam o debate sobre as mutações na cultura escrita. Os efeitos econômicos e simbólicos ocasionados pela civilização da tela, cujas novas estrelas são os e-books, tablets, smartphones, 
também estão na base da discussão sobre a crise do mercado do livro impresso. Hoje, o mercado editorial brasileiro é confrontado com as lógicas da concentração (aquisições e fusões) e da mundialização e, em consequência, a situação apresenta tendência inversa à da década de 1970 . A crise do mercado livreiro é apontada como uma inabilidade ainda marcante em lidar com os novos suportes da cultura escrita. Mas há posicionamentos divergentes e em disputa quanto ao diagnóstico e às saídas para a crise. Editoras tradicionais imediatamente laçam mão das novas tecnologias como modelos de negócio, a exemplo do comércio online de livros físicos e da leitura digital, o que não deixa de impactar negativamente o consumo direto nas livrarias, sobretudo nas pequenas. Ora, livrarias são locais de encontro, sociabilidade e difusão da cultura em geral. Mas a introdução das tecnologias digitais no processo de produção da cultura escrita impõe uma mutação nas práticas de aquisição de conhecimento e lazer.

Não há respostas conclusivas. Não há consenso sobre a extensão das mutações entre as culturas nacionais. Há pistas que apontam para o convívio ou prolongamento, ainda que difícil pelo uso intensivo da internet, entre os suportes impressos e digitais. Tomemos como ilustração a oferta do e-book no Brasil. Embora o Sindicato Nacional de Editores de Livros (SNEL) não apresente dados de conjunto sobre o desenvolvimento desse produto com relação ao livro tradicional, os resultados da pesquisa "Retratos da leitura no Brasil" nos permitem inferir que há uma discreta participação dos e-books no mercado editorial brasileiro, decepcionando os apocalípticos do livro impresso. Segundo a pesquisa, "o faturamento total com conteúdo digital em 2016 foi de $\mathrm{R} \$ 42.543 .916,96$, o equivalente a 1,09\% do mercado editorial brasileiro, excluindose as vendas ao setor governamental" (CÂMARA BRASILEIRA DO LIVRO et al., 2017b, p. 2). Note-se que a produção e comercialização de conteúdo digital está concentrada especialmente no subsetor de obras gerais, cujo faturamento total em 2016 foi de $\mathrm{R} \$ 24.971 .699,38$, número que equivale a apenas $2,38 \%$ do faturamento do subsetor de obras gerais no mesmo ano ${ }^{4}$.

De fato, a mesma pesquisa aponta que apenas $41 \%$ dos entrevistados “já ouviram falar” de livros digitais" e, dentre eles, somente $26 \%$ chegaram a ler um livro digital (FAILLA, 2016, p. 261). A penetração de dispositivos de leitura específicos para e-books também é muito baixa. Dentre aqueles que já leram um livro digital, apenas $4 \%$ o fizeram em um Kindle, Kobo ou Lev, sendo utilizado, por 56\%, o smartphone e, por 49\%, o computador (FAILLA, 2016). Além disso, na maioria dos casos, o acesso ao livro digital não é feito por meio de compra. Até $2015,88 \%$ dos leitores declararam ter baixado o conteúdo gratuitamente pela internet (FAILLA, 2016).

As práticas de leitura no meio digital não se restringem aos e-books. Das quatro principais práticas realizadas pelos usuários da internet, detectadas pela mesma pesquisa, três envolvem, de alguma forma, leitura e escrita, a saber: a) as trocas de mensagens (por meio dos aplicativos Whatsapp e Snapchat); b) a troca de e-mails; c) o acesso a redes sociais, blogs e fóruns de discussão; d) escutar música (FAILLA, 2016). A pesquisa também fornece dados sobre atividades

4 Referimo-nos aqui ao faturamento total do subsetor de obras gerais, que engloba as vendas de livros físicos e digitais. 
na internet especificamente ligadas à leitura. A leitura de notícias e informações em geral é a principal delas, com 52\% de indicações. Dentre as 11 atividades elencadas na pesquisa, a leitura de livros ocupa apenas o $6^{\circ}$ lugar (15\%), perdendo para os estudos e pesquisas para trabalhos escolares (35\%), o aprofundamento sobre temas de interesse (32\%), o compartilhamento em blogs, fóruns ou redes sociais sobre literatura, temas de livros, autores etc. (19\%), e a leitura de jornais, com 16\% das respostas (FAILLA, 2016). Nota-se, finalmente, que a leitura digital tem porcentagem relativamente baixa em quase todas as faixas etárias. Destaca-se, apenas, entre aqueles com 18 a 24 anos - 21\% usam a internet para leitura de livros. Nessa faixa etária, 16\% utilizam a internet para buscar informações sobre "literatura, temas de livros, autores, trechos de livros, editoras, lançamentos" (FAILLA, 2016, p. 259-60).

Os dados consolidados indicam a convivência fértil, mas também conflituosa, entre os meios impressos, eletrônicos e digitais. Neste sentido, o conjunto de artigos que compõem este dossiê aborda a cultura escrita sem, contudo, hierarquizar os suportes ou gêneros analisados em alta, média ou baixa cultura. O propósito é evidenciar um fio condutor que identifique teórica e metodologicamente, na variedade temática aqui reunida, as diferentes formas que a cultura escrita pode assumir, representar e tensionar, ao longo de sua história e na atualidade.

Ao longo do século XX, as histórias em quadrinhos se difundiram entre leitores de todas as classes sociais, criando um dos mais representativos fenômenos de clubes de fãs, com seus fanzines, encontros e uma série de outras atividades. Veiculadas pelos meios impressos (jornais e revistas), as HQs dialogaram com o cinema e a televisão, tornando-se cada vez mais próximas do cotidiano de seus aficionados, o que se evidencia nas convenções dos seguidores de seus diversos mundos imaginários e nas práticas de cosplay. Marco Antonio de Almeida analisa a questão da cultura escrita a partir da história das HQs, tendo como objetivo central a discussão sobre o momento atual, no qual, as tecnologias digitais alteram profundamente o cenário sociocultural. No que diz respeito às HQs, o autor percebe a emergência de novas formas de expressão ligadas à representação identitária, inviáveis no universo dos quadrinhos impressos, dominado pelas grandes editoras.

Giulia Crippa nos convida a pensar a cultura escrita para além do livro. Partindo da proximidade do livro com a narração, a autora extrapola a dimensão da escrita textual, conduzindo-nos a apreciar suas representações artísticas. Em suas palavras, “o intuito é configurar as representações do imaginário acerca do livro e da leitura em um momento em que, diante das novas tecnologias de informação e comunicação, se discutem seu futuro e o das novas relações de leitura proporcionadas por essas tecnologias". Para tanto, a autora traz à discussão a questão das relações entre ilustração e texto escrito, bem como a apropriação artística de determinados títulos literários, transformados em quadros, instalações etc. Trabalhando na esteira da História Cultural ligada à "antropologia visual", a autora acaba por nuançar os debates contemporâneos sobre o livro e as tecnologias, desestabilizando a dicotomia entre escritura e imagem, ou seja, mostrando livros que são para ser vistos. 
Clóvis Brito problematiza o entendimento da cultura escrita a partir de uma prática que, na sociedade contemporânea, tem se expandido de maneira inédita: a musealização. Propõe - como já indica o título do artigo - que o trabalho de musealização é um dos mecanismos que produzem e mantêm determinada leitura e interpretação do objeto musealizado, no caso, a poesia e o poeta Fernando Pessoa. O artigo passeia pela Casa-Museu Fernando Pessoa, em Lisboa, procurando mostrar que a exposição museológica é um texto, uma escritura feita de objetos que cercaram a vida do homenageado. Por outro lado, argumenta que a literatura também é dotada de materialidade, vale dizer, que a literatura de Fernando Pessoa é constituída pelos seus textos e pelo que a Casa Fernando Pessoa, agora potencializada com novas tecnologias, faz com que ela seja.

O artigo de Mariza Werneck sobre o Livro das Mil e Uma Noites aborda as relações entre a cultura escrita, a literatura e o imaginário. Por meio de pesquisa minuciosa, a autora nos dá conta da incansável batalha instaurada entre os diversos tradutores do Livro das Noites para as diversas línguas europeias, desde o século XVIII. As disputas tinham como foco a autenticidade de cada versão, motivo pelo qual, sempre era necessário contestar a tradução anterior, o que era alimentado pela suposta existência de um manuscrito desaparecido que, afinal, havia sido encontrado pelo novo tradutor. A autora nos convida a refletir sobre a tênue fronteira entre o real e o imaginário (o mito, a literatura, a escrita poética), limiar no qual oscila o Livro das Mil e Uma Noites. Condenado a ser eternamente reescrito, o livro, situado entre o oral e o escrito, parece ser o melhor exemplo da perenidade da cultura escrita. "Metáfora da literatura", poderia, como ela, ser definido como a "eterna tentativa de recuperar esse texto original".

\section{Referências}

ANDERSON, Benedict. Nação e consciência nacional. São Paulo: Ática, 1989.

BOURDIEU, Pierre. O poder simbólico. Rio de Janeiro: Bertrand Brasil, 2003.

CÂMARA BRASILEIRA DO LIVRO et al. Desempenho real do mercado livreiro: uma análise de 10 anos da pesquisa produção e vendas do setor editorial brasileiro. São Paulo, 2017a. Disponível em: https://snel.org.br/wp/ wp-content/uploads/2018/02/desempenho-do-mercado.pdf. Acesso em: 6 jun. 2019.

CÂMARA BRASILEIRA DO LIVRO et al. Censo do Livro Digital: ano base 2016. São Paulo, 2017b. Disponível em: https://snel.org.br/pesquisas/\#1535467922268-4b0d099d-eca3. Acesso em: 6 jun. 2019.

CÂMERA BRASILEIRA DO LIVRO et al. Setor editorial brasileiro encolheu 25\% entre 2006 e 2018. São Paulo, 2018. Disponível em:

https://snel.org.br/pesquisas/\#1535467922268-4b0d099d-eca3. Acesso em: 6 jun. 2019.

CANDIDO, Antonio. A revolução de 1930 e a cultura. Novos estudos CEBRAP, São Paulo, v. 2, n. 4, p. 27-35, 1984.

CHARÃO, Cristina; COSTA, Henrique. Tiragens aumentam, mas há gargalos importantes. Desafios do desenvol-

vimento. Ipea, Brasília, ano 10, 76 ed., 25 fev. 2013. Disponível em: http://www.ipea.gov.br/desafios/index.php?option=com_content\&view=article\&id=2912: catid=28\&Itemid=23. Acesso em: 6 jun. 2019.

CHARTIER, Roger. Cultura escrita, literatura e história: conversas de Roger Chartier com Carlos Aguirre Anaya, 
Jesús Anaya Rosique, Daniel Goldin e Antonio Saborit. Porto Alegre: ARTEMED Editora, 2001.

CHARTIER, Roger. Os desafios da escrita. São Paulo: Editora UNESP, 2002.

EBIT. WebShoppers. O mais completo relatório sobre o mercado de e-commerce. 34 ed. 2016. Disponível em: https://www.ebit.com.br/webshoppers. Acesso em: 12 jun. 2019.

RIELO, Adilson. A venda de livros, a situação dos e-books e o que o e-commerce tem com isso. Ecommerce Brasil, 2017. Disponível em:

https://www.ecommercebrasil.com.br/artigos/venda-de-livros-situacao-dos-e-books-e-o-que-o-e-commerce-tem-com-isso/. Acesso em: 5 jun. 2019.

ESCARPIT, Robert. A revolução do livro. Rio de Janeiro: FGV; INL, 1976.

RODRIGUES, Maria Fernanda. O que está acontecendo com o mercado editorial em cinco perguntas. Exame, São Paulo, 27 dez. 2018. Disponível em:

https://exame.abril.com.br/negocios/o-que-esta-acontecendo-com-o-mercado-editorial-em-cinco-perguntas/. Acesso em: 5 jun. 2019.

FAILLA, Zoara (org.). Retratos da Leitura no Brasil 4. Rio de Janeiro: Sextante, 2016.

FEBVRE, Lucien. Lapparition du livre. Paris: A. Michel, 1958.

TRIGO, Luciano. Crise do mercado editorial revela falência de um modelo. Pop \& Art. Blog do Luciano Trigo. G1, 1 dez. 2018. Disponível em: https:/g1.globo.com/pop-arte/blog/luciano-trigo/post/2018/12/01/crise-do-mercado-editorial-revela-falencia-de-um-modelo.ghtml. Acesso em 14 de junho de 2019.

GELLNER, Ernest. Nações e nacionalismo. Lisboa: Gradiva, 1993.

HALLEWELL, Laurence. O livro no Brasil: sua história. São Paulo: T. A. Queiroz; Edusp: 1985.

LE GOFF, Jacques. Os intelectuais na Idade Média. Lisboa: Gradiva, 1984.

LYONS, Martyn. Le triomphe du livre: une histoire sociologique de la lecture dans la France du XIXe. siècle. Paris: Promodis, 1987.

MARTÍN-BARBERO, Jesus. De los medios a las mediaciones. Comunicación, cultura y Hegemonía. Barcelona: Gustavo Gili, 1987.

MCKENZIE, Donald Francia. La bibliographie et la sociologie des textes. Paris: Éditions du Cercle de la Librairie, 1991.

ORTIZ, Renato. A moderna tradição brasileira: Cultura brasileira e indústria cultural. São Paulo: Editora Brasiliense, 1988.

ORTIZ, Renato. Cultura e Modernidade: a França no século XIX. São Paulo: Editora Brasiliense, 1991.

ORTIZ, Renato. Mundialização e Cultura. São Paulo: Editora Brasiliense, 1994.

PAIXÃO, Fernando. Momentos do livro no Brasil. São Paulo: Editora Ática, 1995.

PUBLISHNEWS. Assim foi o mercado editorial em 2018. Blog da Redação. São Paulo, 21 dez. 2018. Disponível em: https://www.publishnews.com.br/materias/2018/12/21/assim-foi-o-mercado-editorial-em-2018. Acesso em: 6 jun. 2019.

WILLIAMS, Raymond. The Long Revolution. Londres: Penguin Books, 1984.

Recebido em: 04/03/2020

Aceito em: 05/03/2020 